\title{
Pemanfaatan YouTube sebagai Media Pembelajaran Vokal Pop Jazz di Prodi Pendidikan Musik Institut Seni Indonesia Yogyakarta
}

\author{
Suryati ${ }^{1}$ \\ Program Studi Pendidikan Musik, Fakultas Seni Pertunjukan, Institut Seni Indonesia Yogyakarta
}

\begin{abstract}
Utilizing Youtube as a Learning Media for Pop-Jazz Vocal Course at Music Education Study Program of Institut Seni Indonesia Yogyakarta. The research aims to reveal the learning process of the Pop-Jazz vocal course and the utilization of youtube as an accompaniment in learning the PopJazz vocal course. This research is expected to provide solutions for students who face problems in the learning process of the Pop-Jazz vocal course during the covid-19 pandemic. It is qualitative research with a case study approach. Data collection techniques were carried out through direct observation during the learning process. Furthermore, interviews with teachers and vocal students of Pop-Jazz were conducted to obtain the data. It was a case study of vocal students of Pop-Jazz Intermediate 1 at the Music Education Study Program. The literature studies were carried out to support the data and references. This study shows that the interest in vocal learning of Pop-Jazz at the Music Education Study Program by utilizing youtube as an accompaniment at the pop-jazz vocal course can be increased.
\end{abstract}

Keywords: learning; pop-jazz vocal; YouTube; Music Education Study Program

\begin{abstract}
ABSTRAK
Penelitian ini bertujuan untuk mengungkapkan proses pembelajaran mata kuliah vokal Pop Jazz dan Pemanfaatan youtube sebagai iringan dalam pembelajaran mata kuliah vokal Pop Jazz. Penelitian ini diharapkan dapat memberikan solusi bagi mahasiswa yang menghadapi permasalahan dalam proses pembelajaran mata kuliah vokal Pop Jazz pada masa pademi covid-19. Penelitian ini menggunakan jenis penelitian kualitatif dengan pendekatan studi kasus. Teknik pengumpulan data dilakukan melalui, observasi langsung pada saat proses pembelajaran. Selanjutnya dilakukan wawancara dengan pengajar dan mahasiswa vokal Pop Jazz. Dalam hal ini mengambil sampel studi kasus mahasiswa vokal Pop Jazz lanjut 1 di Prodi Pendidikan Musik. Kemudian untuk mendukung kelengkapan data dan bahan acuan sebagai referensi dilakukan studi pustaka. Hasil penelitian ini menunjukkan bahwa dengan pemanfaatan YouTube sebagai iringan dalam mata kuliah vokal Pop Jazz dapat meningkatkan minat pembelajaran vokal Pop Jazz di Prodi Pendidikan Musik. Sangat mendukung proses pembelajaran, karena lebih efektif dan mahasiswa bisa berlatih secara mandiri dengan aplikasi YouTube. Selain itu mahasiswa lebih terkendali dalam mengekspreikan dan memberikan improvisasikan lagu.
\end{abstract}

Kata kunci: pembelajaran; vokal pop jazz; YouTube; Prodi Pendidikan Musik

\section{Pendahuluan}

Pada masa pandemi covid-19, telah mengubah berbagai aktivitas kehidupan manusia, termasuk dunia pendidikan diseluruh Indonesia.
Dengan adanya pandemi covid-19, pemerintah mengeluarkan kebijakan tentang proses pembelajaran dengan jarak jauh atau diadakan secara daring bagi seluruh janjang pendidikan termasuk juga jenjang Perguruan Tinggi

Alamat korespondensi: Program Studi Pendidikan Musik, Fakultas Seni Pertunjukan, Institut Seni Indonesia Yogyakarta. Jalan Parangtritis Km. 6,5 Sewon Bantul Yogyakarta. E-mail: atik.jurasik@yahoo.com; HP.: 085872874142 . 
(Herliandry et al., 2020). Strategi dalam memutus penyebaran covid-19 di Pendidikan Tinggi maka dilakukan dengan pilihan pembelajaran secara daring (Yudiawan, 2020). Oleh sebab itu satusatunya cara yang bisa digunakan dalam proses pembelajaran pada masa pandemi COVID-19 yaitu pembelajaran online (Pujiasih, 2020). Hal ini juga ditegaskan Menteri Agama bahwa penyelenggaraan pendidikan harus mempertimbangkan kesehatan dengan mengedepankan pelayanan pendidikan secara daring. Pembelajaran secara daring ini membutuhkan teknologi dengan menggunakan layanan internet secara online. Teknologi Komunikasi yaitu penggunaan alat bantu untuk memproses dan mentransfer segala hal yang berkaitan dengan data dari perangkat satu ke perangkat lainnya (Putri Sola et al., 2015). Dalam proses pembelajaran yang dilakukan secara daring tentu saja terdapat kekurangan dan kelebihannya. Hal ini berimbas pada proses pembelajaran di Prodi Pendidikan Musik Fakultas Seni Pertunjukan Institut Seni Indonesia Yogyakarta. Materi perkuliahan yang diberikan di Prodi Pendidikan Musik diberikan secara teori dan praktik. Kurikulum yang diterapkan di Prodi Pendidikan Musik tertera dalam sebaran mata kuliah semester satu hingga semester delapan.

Vokal Pop Jazz adalah salah satu mata kuliah praktik instrumen mayor yang dipilih oleh mahasiswa Prodi Pendidikan Musik. Istilah jenis musik Pop atau Populer adalah musik yang berasal dari Amerika, dalam kurun waktu yang cukup lama seperti halnya penyanyi Frank Sinatra (Bintarto, 2014). Tidak jauh berbeda dengan musik Jazz tumbah sudah cukup lama pada awal abad ke-20, atau sekitar pada tahun 1920-an (B. Koapaha, 2013). Mata kuliah Vokal Pop Jazz sebagai instrumen mayor ini berjenjang dari semester satu hingga semester lima. Mata kuliah berjenjang ini jika pada tingkat satu belum lulus, maka tidak mengambil jenjang selanjutnya. Pembelajaran mata kuliah praktik vokal Pop Jazz dilakukan secara individu dan kelompok. Dalam proses pembelajarannya dengan menggunakan instrumen minimal piano atau keyboard yang berfungsi sebagai iringan. Akan tetapi pada waktu Ujian Tengah Semester dan Ujian Akhir Semester para mahasiswa vokal
Pop Jazz kebanyakan menggunakan iringan yang lengkap yaitu kombo band. Hal ini tidak mungkin lagi dilakukan pada masa pandemi covid-19 yang sudah melanda Indonesia selama satu tahun lebih, dan sampai kapan akan berakhir. Oleh karena itu, untuk mengatasi hal tersebut dapat menggunakan teknologi dengan memanfaatkan YouTube sebagai alternatif iringan dalam proses pembelajaran praktik vokal Pop Jazz di masa pandemi covid-19. Pandemi covid-19 secara tiba-tiba mengaharuskan elemen pendidikan untuk mempertahankan pembelajaran secara online. Hal ini sesuai dengan pembelajaran di Era digital ini bahwa pembelajarn yang efektif menggunakan teknologi, apalagi pada saat Pandemi covid-19 (Pujiasih, 2020). Oleh karena itu penguasaan teknologi sangatlah urgen dibutuhkan tidak hanya dikalangan mahasiswa saja, akan tetapi juga bagi dosen sebagai pengajar. Pengajar di era masa kini harus lebih terbuka dalam mendidik dengan mengikuti pemikiran-pemikiran baru sesuai zamannya, dengan batasan tidak melanggar norma yang berlaku (Africa et al., 2020).

YouTube adalah sebuah jaringan media sosial yang mudah diakses dan banyak diminati oleh segala usia dari anak-anak hingga orang dewasa. Perkembangan teknologi yang semakin pesat, maka segala pengetahuan dan ketrampilan dengan mudah dapat diakses melalui YouTube. Oleh karena itu YouTube dapat dimanfaatkan sebagai salah satu media ajar yang banyak disukai para mahasiswa (Mujianto, 2019). Pembelajaran secara online dapat menginspirasi para pengajar untuk dapat mengembangkan media pembelajaran dengan teknologi. Media pembelajaran sangat bermanfaat dalam membantu proses pembelajaran secara optimal dan mempermudah interaksi antara pengajar dan siswa, sehingga tujuan pembelajaran akan tercapai (Rizkiansyah, 2015). Aplikasi YouTube dapat mengakses berbagai macam jenis lagu termasuk Pop dan Jazz, baik instrumental maupun dengan vokal. Adanya aplikasi YouTube dapat dimanfaatkan sebagai media pembelajaran vokal Pop Jazz, baik untuk penyampaian materi lagu hingga iringan lagu berbentuk karaoke atau minus one. Lagu tanpa vokal yang berbentuk karaoke yang diakses melalui YouTube dapat dijadikan iringan dalam pembelajaran vokal 
Pop Jazz Melalui aplikasi YouTube penyampaian materi ajar akan lebih mudah dipahami bagi para mahasiswa. Oleh karena itu pemanfaatan YouTube dalam proses pembelajaran vokal Pop Jazz dapat membantu para mahasiswa untuk memperoleh bahan ajar (Purwandari, 2019).

Berkaitan dengan permasalahan yang dihadapi para mahasiswa vokal Pop Jazz di Prodi Pendidikan musik dalam proses pembelajaran di masa pandemi covid 19, maka diperlukan suatu strategi media pembelajaran. Oleh karena itu sangat urgen untuk diteliti sebagai bentuk solusi pemecahan masalah dalam mencari iringan lagu di YouTube yang akan dinyanyikan oleh mahasiswa vokal Pop Jazz. Penelitian ini akan membahas dua permasalahan yaitu bagaimana proses pembelajaran vokal Pop Jazz dan bagaimana pemanfaatan YouTube sebagai media pembelajaran khususnya iringan dalam Proses pemebelajaran vokal Pop Jazz yang dilakukan di Prodi Pendidikan Musik di masa pandemi covid-19.

\section{Metode Penelitian}

Penelitian ini, menggunakan metode penelitian kualitatif dengan pendekatan studi kasus (Case Study) untuk pemecahan masalah (Gustianingrum \& Affandi, 2016). Sugiyono menjelaskan bahwa metode penelitian kualitatif adalah metode penelitian yang berlandaskan pada fisafat postpositivisme, yang digunakan untuk meneliti pada kondisi objek ilmiah (Meinawati, 2020). Studi kasus termasuk dalam penelitian analisis deskripsi, yang dimaksud disini adalah penelitian yang dilakukan terfokus pada suatu kasus tertentu untuk diamati dan dianalisis secara cermat. Raharja menjelaskan bahwa studi kasus adalah metode penelitian dengan subjek penelitian secara terbatas yaitu individu, kelompok, lembaga, maupun kelompok masyarakat (Raharja, 2021). Menurut Sugiyono metode deskripsi adalah suatu metode yang digunakan untuk menggambarkan atau menganalisis suatu hasil penelitian tetapi tidak digunakan untuk membuat kesimpulan yang lebih luas (Sugiyono, 2011). Penelitian case study atau penelitian lapangan (field study) dimaksudkan untuk mempelajari secara intensif tentang latar belakang masalah keadaan dan posisi suatu peristiwa yang sedang berlangsung saat ini, serta interaksi lingkungan unit sosial tertentu yang bersifat apa adanya (given). Subjek penelitian dapat berupa individu, kelompok, institusi atau masyarakat. Dalam hal ini studi kasus sebagai objek penelitian adalah permasalahan yang dihadapi pada proses pembelajaran praktik instrumen mayor vokal Pop Jazz di Prodi Pendidikan Musik ISI Yogyakarta.

Penelitian ini secara kronologis dapat dilakukan melalui beberapa tahapan teknik pengumpulan yaitu studi lapangan (observasi), studi pustaka, studi lapangan dan analisis data. Observasi dilakukan langsung untuk mengamati dalam proses pembelajaran praktik vokal Pop Jazz di Prodi Pendidikan ISI Yogyakarta (Pandaleke \& Jazuli, 2016). Lebih jelas dikatakan oleh Rohidi bahwa metode observasi digunakan untuk mengamati sesuatu, seseorang, situasi lingkungan dengan secara rinci dan akurat, dengan berbagai cara (Rohidi, 2011). Selanjutnya untuk memperoleh data-data yang tidak dapat dilakukan melelui observasi, maka dilakukan wawancara secara daring bagi mahasiswa instrumen mayor vokal Pop Jazz . Penelitian studi lapangan sangat dilakukan untuk mendapatkan data-data tentang objek yang diteliti melalui observasi, wawancara dengan nara sumber atau informan, dan pendokumentasian pada proses pembelajaran praktik instrumen mayor vokal Pop Jazz secara daring (Gustianingrum \& Affandi, 2016).

Selanjutnya setelah melalui proses pengumpulan data-data yang didapat dari hasil studi pustaka dan studi lapangan kemudian dilakuan pengolahan data dan menganalisis data secara kualitatf. Dalam hal ini dianalisis secara tajam terhadap berbagai faktor yang terkait dengan kasus tersebut, sehingga akan diperoleh kesimpulan yang akurat (Sutedi, 2009). Pengumpulan data dan pengolahan data dibantu oleh salah satu anggota dari mahasiswa yang bernama Aulia Pramesti Rizki Utami. Tahapan-tahapan yang dilakukan penelitian di atas, maka diharapkan dapat memberikan informasi atau data-data yang akurat sehingga dapat dioah dan dianalisis menjadi hasil penelitian proses pembelajaran praktik instrumen mayor vokal Pop Jazz dan pemanfaatan YouTube sebagai media pembelajaran praktik instrumen mayor vokal Pop 
Jazz di Prodi Pendidikan Musik ISI Yogyakarta di masa pandemi covid-19.

\section{Hasil dan Pembahasan}

Pembahasan ini akan memaparkan hasil penelitian tentang pemanfaatan YouTube sebagai media pembelajaran praktik instrumen mayor vokal Pop Jazz di Prodi Pendidikan Musik Institut Seni Indonesia Yogyakarta. Penelitian ini akan membahas dua permasalahan. Pembahasan pertama tentang proses pembelajaran praktik instrumen mayor vokal Pop Jazz, dan pembahasan kedua tentang Penerapan pemanfaatan YouTube sebagai media pembelajarannya. Dalam hal ini akan terfokus pada kelas praktik instrumen mayor vokal Pop Jazz lanjut I. Proses pembalajaran mata kuliah praktik instrumen mayor vokal Pop Jazz lanjut I dalam satu semester pada umumnya dapat dilakukan dengan 14 kali pertemuan materi, 1 kali Ujian Semester dan 1 kali Ujian Akhir semester, baik dilakukan secara daring maupun luring.

Pada pertemuan kuliah pertama dilakukan secara daring Bersama-sama dalam satu kelas melalui zoom meeting. Pada pertemuan ini, belum memberikan materi, masih pengantar penyampaian kontrak kuliah, Rencana Pembelajaran Semester (RPS), dan materi yang akan diberikan dalam satu semester. Selanjutnya untuk mengawali materi perkuliahan diberikan beberapa pilihan lagu yang diambilkan dari aplikasi YouTube. Lagu tersebut sebagai bahan yang harus dilatih oleh mahasiswa secara mandiri, untuk mempersiapkan pertemuan berikutnya. Setiap mahasiswa harus mempersiapkan 2 lagu yaitu satu lagu Pop dan satu lagu Jazz.

Pada pertemuan berikutnya yaitu pertemuan kedua juga dilakukan secara daring, materi yang diberikan tentang teknik menyanyi yang baik dan benar, baik secara teori maupun praktik. Hal ini dilakukan agar dalam memproduksi suara dapat menghasilkan suara dengan teknik vokal yang benar. Pada pertemuan ketiga hingga kedelapan praktik vokal Pop Jazz lanjut I dilakukan secara daring dan luring. Praktik secara daring bagi mahasiswa yang tinggal di luar Yogyakarta dan praktik secara luring bagi mahasiswa yang tinggal di Yogyakarta. Akan tetapi lebih banyak yang mengikuti perkuliahan praktik vokal secara daring karena mahasiswa lebih banyak yang tinggal di luar Yogyakarta dan kondisi sekitar kampus termasuk zona merah. Proses pembelajarannya baik secara daring ataupun luring diawali dengan latihan pernapasan yang benar untuk menyanyi yaitu pernapasan diafragma. Latihan pernapasan dapat menggunakan nada-nada panjang agar dapat mengontrol pernapasan dalam mengatur keluarnya napas. Berikut contoh nadanada panjang untuk latihan pernapasan.

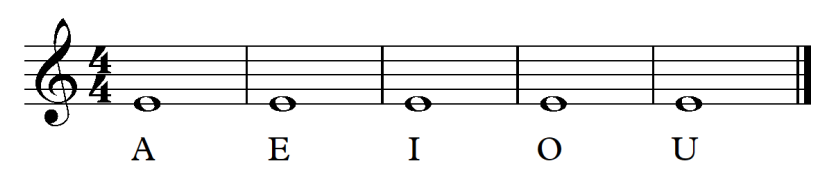

Notasi 1: Nada panjang untuk latihan pernapasan dengan huruf vokal.

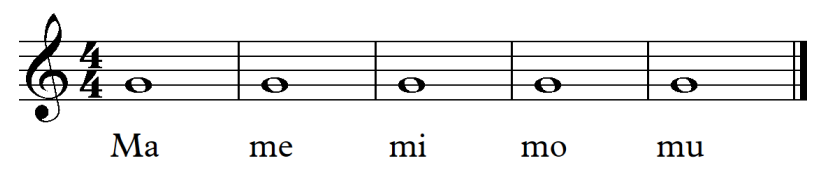

Notasi 2: Nada panjang untuk latihan pernapasan dan memperbesar resonansi dengan huruf konsonan dan vokal.

Setelah melakukan latihan pernapasan dengan benar dilanjutkan pemanasan (Warming-up) vokalisi beberapa variasi, untuk memproduksi suara yang baik dan benar, ini dilakukan secara kelompok dan individu. Manfaat materi pemanasan ini juga sebagai latihan dalam mencapai nada-nada rendah dan tinggi dengan benar. Selain itu juga untuk melatih artikulasi huruf vokal a, e, i, o, u dan pemanfaatan rongga resonansi yang benar. Berikut contoh beberapa variasi pemanasan (Warming-up) untuk vokalis dalam pembentukan suara.

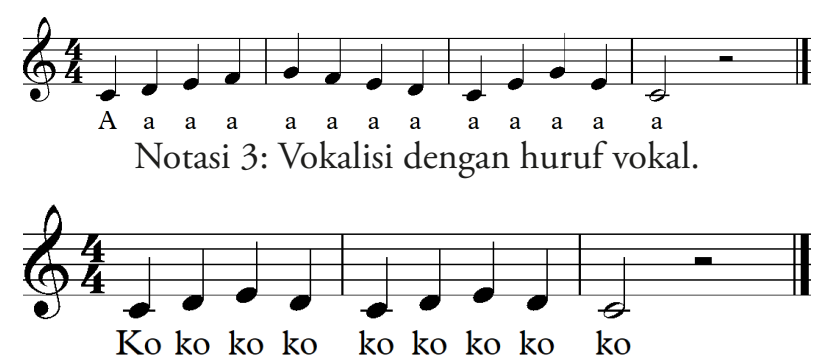

Notasi 4: Vokalisi dengan suku kata ko untuk memperkuat dinding resonansi.

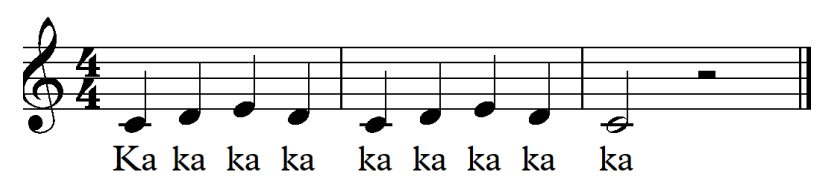

Notasi 5: Vokalisi dengan suku kata ka untuk memperkuat dinding resonansi. 


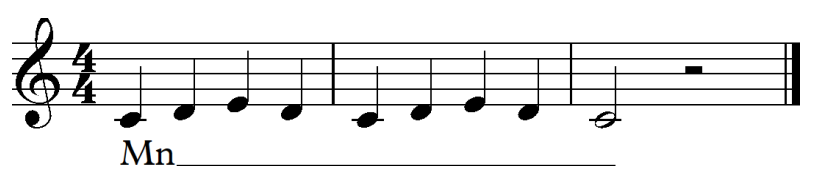

Notasi 6: Vokalisi dengan huruf $M$ untuk melatih dinding-dinding resonansi.

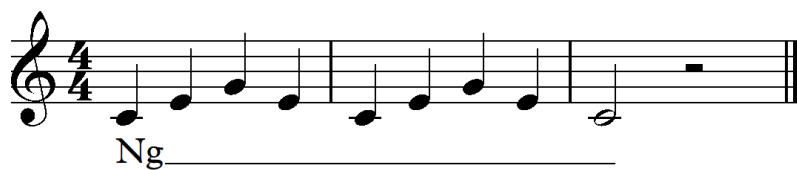

Notasi 7: Vokalisi dengan huruf $\mathrm{Ng}$ untuk melatih dinding-dinding resonansi.

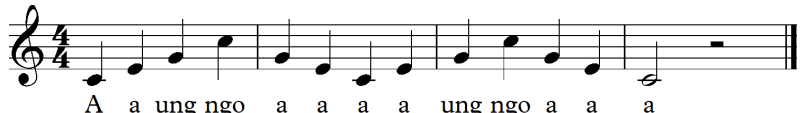

Notasi 8: Vokalisi untuk melatih dinding-dinding resonansi dan register nada-nada rendah, sedang dan tinggi.

Pada saat melakukan pemanasan pengajar memainkan piano mahasiswa menirukannya. Hal ini jika dilakukan secara daring, akan mengalami kendala karena bunyi piano yang sampai di pendengaran mahasiswa terkesan terlambat. Oleh karena itu dengan cara tersebut mahasiswa lebih sulit untuk mengikutinya. Setelah melakukan pemanasan dilanjutkan dengan mempraktikan salah satu materi lagu dari YouTube yang sudah diberikan pada pertemuan sebelumnya. Pada saat melakukan praktik vokal dengan menyanyikan lagu diperlukan suatu iringan, karena menyanyi tidak terlepas dengan iringan. Sebelum masa pandemi proses pembelajaran praktik vokal dilakukan secara luring dan bisa menggunakan iringan piano atau keyboard. Akan tetapi sudah hampir 3 semester pada saat pandemi Covid-19 proses pembelajaran praktik vokal Pop Jazz mengalami kendala pada iringan. Oleh karena itu untuk mengatasi hal tersebut dapat ditawarkan solusi atau alternatif iringan pada saat pembelajaran daring berlangsung dengan memanfaatakan aplikasi YouTube.

Dalam pembelajaran praktik Vokal Pop Jazz dengan aplikasi YouTube sangat dibutuhkan sebagai media iringan. Hal ini telah berlangsung dalam proses pembelajaran praktik Vokal Pop Jazz. Setelah empat kali pertemuan mahasiswa diminta mengirimkan ke google classroom.video rekaman hasil latihan secara mandiri, untuk melihat perkembangan hasil pembelajaran yang telah diberikan. Kemudian setelah dilakukan praktik selama delapan kali pertemuan, maka untuk mengukur keberasilan dalam proses pembelajaran praktik Vokal Pop Jazz dilakukan Ujian Tengah Semester (UTS) pada pertemuan kesembilan. Pada saat Ujian Tengah Semester mahasiswa diminta untuk menyanyikan dua lagu, satu lagu Pop dan satu Lagu Jazz, keduanya berbahasa Inggris. Iringan lagu yang digunakan dengan karaoke dari YouTube atau minus one. Iringan tersebut tentu saja tidak semua sesuai dengan tinggi rendah suara yang diinginkan. Oleh karena itu, untuk menurunkan dan menaikan nada agar sesuai tinggi rendah suara yang dimiliki mahasiswa digunakan aplikasi music speed changer. Music speed changer adalah sebuah aplikasi yang dapat untuk mengubah menurunkan dan menaikan nada, juga dapat mengubah kecepatan sebuah lagu.

Selanjutnya pada pertemuan kesepuluh dapat dijadikan sebagai ajang evaluasi hasil UTS, dan hasilnya akan digunakan untuk perbaikan pada materi selanjutnya. Pada pertemuan kesebelas hingga kelima belas proses pembelajarannya sama seperti sebelumnya yaitu diawali dengan pemanasan vokalisi sebelum masuk materi lagu. Pada pertemuan kesebelas hingga kelima belas ini dalam praktik vokal selain memperbaiki kekurangan yang dilakukan pada UTS. Salah satu kekurangan yang ditemukan sebagian besar dalam mencapai nada rendah dan tinggi, sehingga perlu diberikan teknik vokal untuk mencapai nada tinggi secara berulang-ulang. Selain itu juga beberapa mahasiswa dalam memberikan improvisasi kurang tepat pada akornya, sehingga perlu diberikan teknik improvisasi dalam menyanyikan suatu lagu secara berulang-ulang, hal ini dilakukan secara terus menerus. Untuk mengecek perkembangan hasil perbaikan mahasiswa diminta mengirimkan video rekaman ke google classroom. Kemudian pada pertemuan keenam belas dilakukan checking terakhir semua materi lagu yang akan dibawakan pada saat Ujian Akhir Semester secara individu. Segala kendala, kekurangan yang terdapat pada rekaman lagu yang dikirimkan akan disampaikan agar dapat diperbaiki dan dipersiapkan pada waktu Ujian Akhir Semester.

Proses pemanfaatan YouTube sebagai media iringan dalam praktik instrumen mayor vokal, akan mengambil beberapa sempel lagu yang 
dinyanyikan oleh mahasiswa kelas vokal Pop Jazz lanjut I. Sebelum dilakukan penerapan YouTube sebagai media iringan dalam praktik vokal, terlebih dahulu semua mahasiswa kelas praktik vokal pop Jazz lanjut I diminta melakukan proses download lagu yang akan dinyanyikan masing-masing secara mandiri. Sempel yang pertama atas nama Titisari Teresa akan menyanyikan lagu Pop yang berjudul I Surender dari lagu yang dinyanyikan oleh Celine Dion. Setelah lagu berhasil di download, kemudian dipelajari secara mandiri terlebih dahulu. Hasil dari latihan secara mandiri dikonsultasikan dan dipraktikan bersama pengajar secara daring. Selanjutnya setelah mendapatkan lagu dan sudah bisa menyanyikan lagu tersebut dengan melodi yang benar, dilakukan pembelajaran praktik lagu tersebut dengan iringan secara rutin. Oleh karena itu diberikan cara bagaimana proses penerapan YouTube sebagai media iringan lagu sesuai tinggi rendah suara yang dimiliki. Proses tersebut dilakukan dengan beberapa tahapan. Tahapan pertama melakukan download lagu $I$ Surender tanpa vokal atau karaoke melalui aplikasi YouTube. Proses ini dilakukan pada saat proses pembelajaran praktik vokal Pop Jazz secara daring, agar semua mahasiswa dapat melakukan bersama-

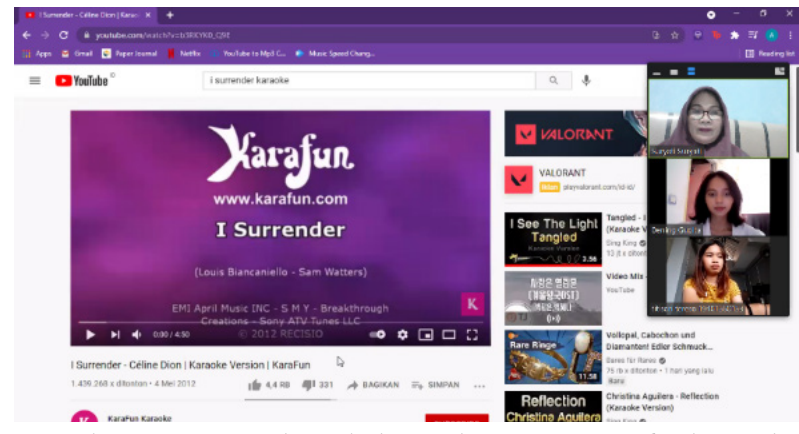

Gambar 1: Tampilan di layar lagu I Surender karaoke oleh Celine Dion.

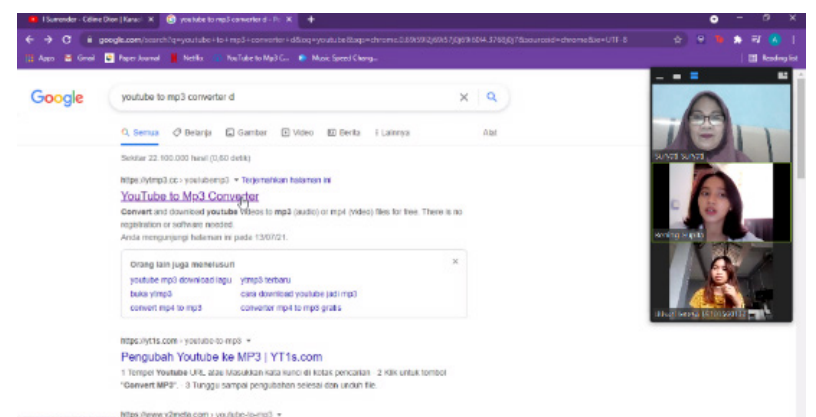

Gambar 2: Tampilan di layar untuk mencari YouTube to $M p 3$ Converter yang dipilih. sama dengan lagu yang berbeda. Langkah pertama yang dilakukan cari YouTube.com, kemudian ketik I Surender karaoke, muncul beberapa pilihan, klik yang "I Surender - Celine Dion /Karaoke Version/ KaraFun". Gambar 1 merupakan tampilan di layar untuk men-download lagu I Surender karaoke oleh oleh Celine Dion.

Setelah berhasil men-download karaoke tersebut, dilanjutkan pada tahapan kedua. Pada tahapan kedua ini meng-convert dari YouTube ke $m p 3$, dengan cara tambah ketik YouTube to $m p 3$ Converter di google, kemudian enter. Setelah diklik kemudian muncul beberapa pilihan, akan tetapi pilih yang YouTube to Mp3 Converter. Gambar 2 merupakan tampilan di layar bentuk YouTube to Mp3 Converter yang dipilih.

Pada tahapan ketiga ini, setelah YouTube to Mp3 Converter diklik akan muncul gambar YtMp3. Langkah selanjutnya yang dilakukan meng-copy link YouTube dari I Surender karaoke https:// www.YouTube.com/watch?v=b3RKYK0_Q9E, di masukan dalam kotak $Y T M p 3$, kemudian diklik convert. Gambar 3 merupakan tampilan di layar proses meng-convert dari YouTube ke mp3.

Setelah selesai meng-convert, kemudian dilanjutkan pada tahapan keempat. Pada tahapan

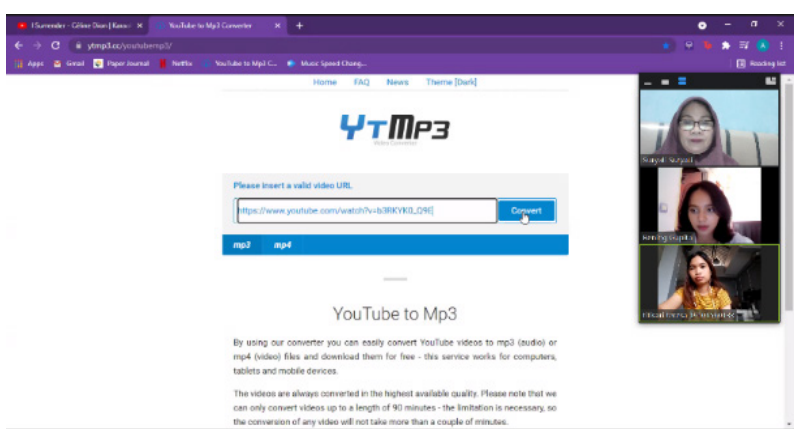

Gambar 3: Tampilan di layar bentuk halaman YouTube to $M p 3$ Converter.

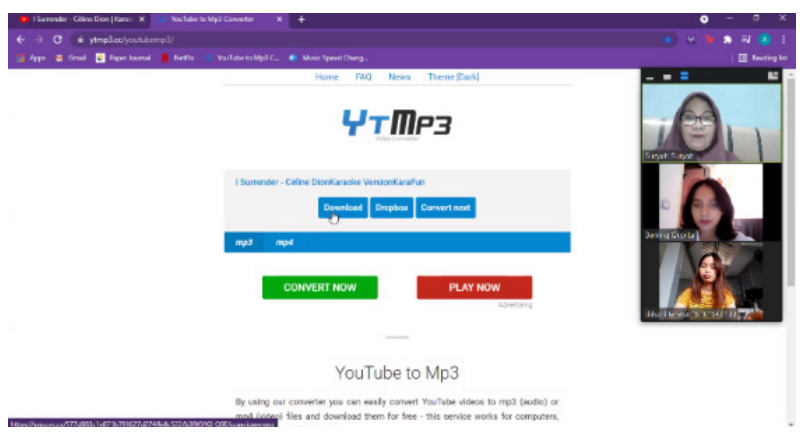

Gambar 4: Tampilan di layar hasil convert dari YouTube to Mp3 Converter. 
keempat ini, men-download lagu yang sudah di convert, dengan cara klik download. Gambar 4 merupakan tampilan di layar hasil convert dari YouTube to Mp3 Converter.

Pada tahapan kelima ini, dilanjutkan proses pembuatan iringan dengan cara tambah ketik music speed changer di google, kemudian di enter akan muncul link https://id.search.yahoo.com/search?fr $=$ mcafee $\&$ type $=E 210 I D 714 \mathrm{G} 0 \& \mathrm{p}=$ music + speed + changer. Setelah mucul link tersebut akan muncul beberapa pilihan, akan tetapi pilih yang Music Speed Changer, Changer Tempo \& Audio. Gambar 5 merupakan tampilan di layar link Music Speed Changer.

Setelah melalui tahapan kelima dengan memilih klik Music Speed Changer, Changer Tempo \& Audio, kemudian muncul link https:// musicspeedchanger.com. Proses convert akan dilanjutkan dengan tahapan keenam. Pada tahapan keenam ini, untuk merubah tinggi rendah suara sesuai yang dimiliki, maka akan diklik Web App. Gambar 6 merupakan tampilan di layar setelah klik music speed changer.com, dan klik Web App.

Proses selanjutnya, pada tahapan ketujuh ini, setelah klik Web App yang terletak di pojok kanan atas akan muncul Choose Audio File, pada

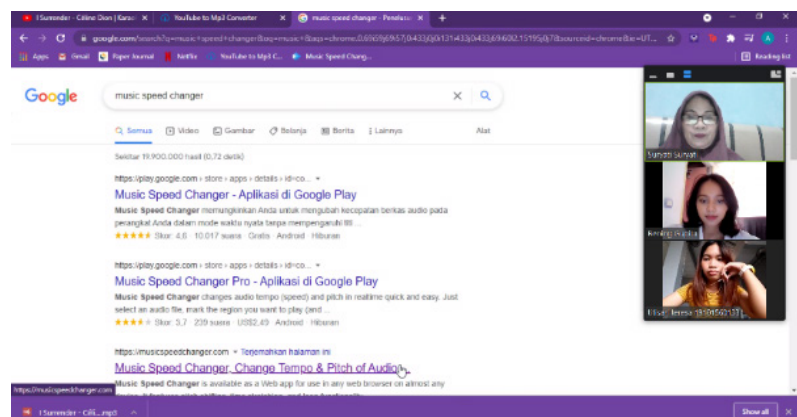

Gambar 5: Tampilan di layar link untuk mencari Music Speed Changer.

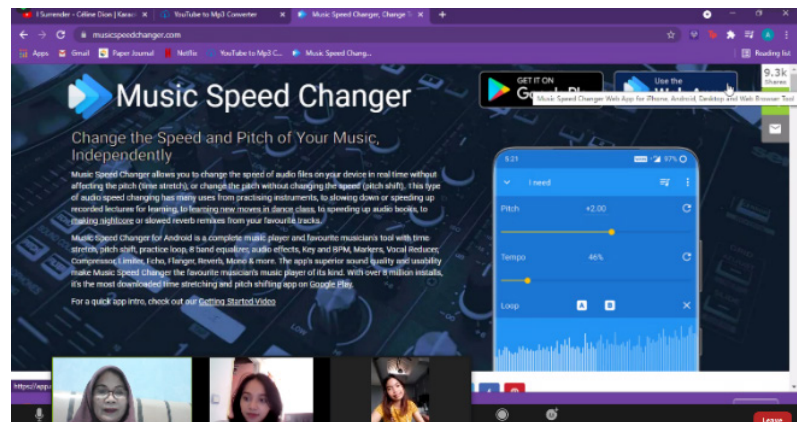

Gambar 6: Tampilan di layar bentuk halaman Music Speed Changer. link https://app.musicspeedchanger.com. Gambar 7 merupakan tampilan di layar Choose Audio File.

Pada tahapan kedelapan, setelah klik Choose Audio File kemudian langsung memilih file lagu I Surender yang telah di download. Pilih file $I$ Surender-Celine DionKaraoke VersionKarafun, kemudian klik dan open. Gambar 8 merupakan tampilan di layar proses klik Choose Audio File pada file lagu yang sudah di download.

Pada proses tahapan kesembilan, setelah klik open akan muncul gambar tanda (+ -) untuk menaikkan dan menurunkan suara atau menambah dan mengurangi kecepatan (tempo). Jika akan menaikkan klik yang tanda (+), dan menurunkan klik tanda (-), sesuai yang dikehendaki. Gambar 9 dan Gambar 10 merupakan tampilan di layar gambar pada link https://app.musicspeedchanger.com.

Pada tahapan kesepuluh ini merupakan tahapan terakhir untuk meng-convert iringan vokal. Setelah suara diturunkan (-2.00) kemudian di save klik di pojok kanan atas. Selanjutnya menunggu proses save selesai, kemudian akan muncul ke file dan sudah berubah dengan nama secara otomatil menjadi file I Surender-Celine Dion Karaoke Version Karafun (Pitch-2.00-Tempo 100). Lagu tersebut sudah diturunkan (-2.00) maksudnya turun 1

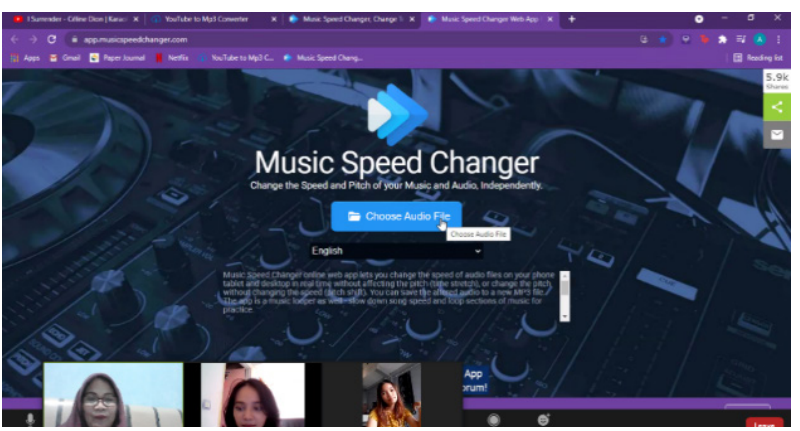

Gambar 7: Tampilan di layar Music Speed Changer menu Choose Audio File.

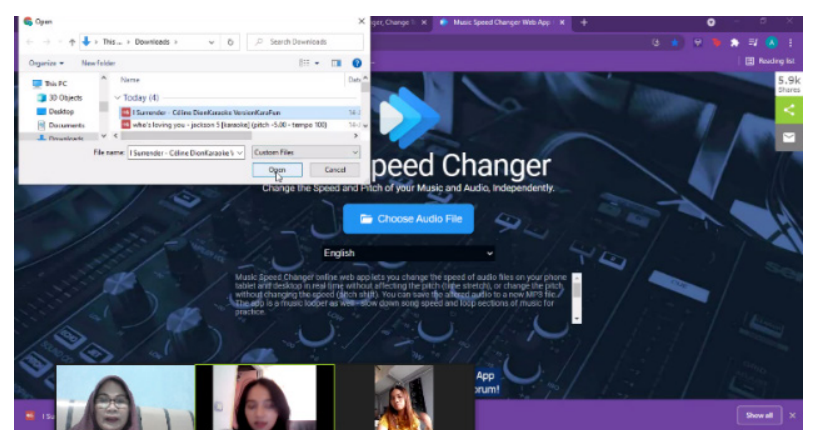

Gambar 8: Tampilan di layar Choose Audio File untuk open file. 
nada, sebagai contoh jika lagu aslinya dengan nada dasar do=G, diturunkan (-2.00) atau turun 1 nada sehingga menjadi nada dasar do=F. Gambar 11 dan Gambar 12 merupakan tampilan di layar cara save file yang sudah di turunkan dan sudah berubah nama secara otomatis di file yang sama.

Proses meng-convert tersebut telah selesai, dan file terbaru sudah dapat digunakan untuk proses pembelajaran praktik vokal Pop Jazz lanjut I. Dengan adanya iringan tersebut mahasiswa dapat berlatih secara mandiri. Hal tersebut salah satu contoh lagu, untuk lagu yang berbeda dengan cara dan proses yang sama dalam mencari iringan. Selanjutnya proses penerapan iringan pada pembelajaran vokal dengan lagu I Surender dapat

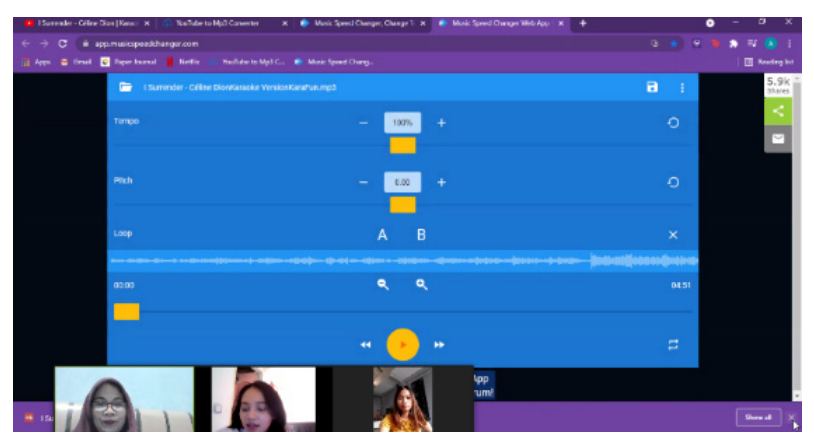

Gambar 9: Tampilan Music Speed Changer di layar masih asli belum dinaikan dan diturunkan.

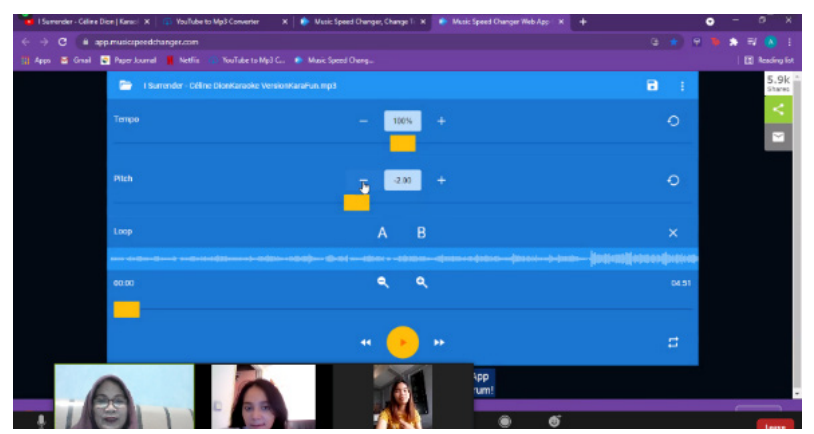

Gambar 10: Tampilan Music Speed Changer di layar sudah diturunkan (-2.00).

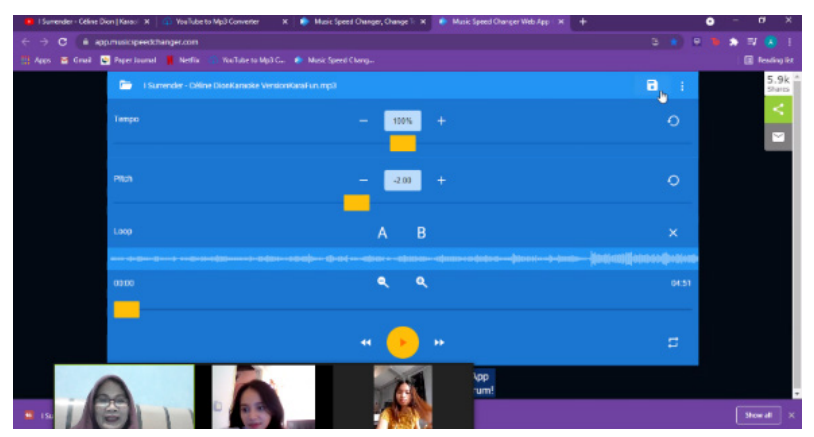

Gambar 11: Tampilan Music Speed Changer di layar cara save file. dilakukan secara rutin. Gambar 13 merupakan proses pembelajaran praktik vokal dengan lagu $I$ Surender atas nama Titisari.

Selain Titisari, sempel yang kedua pada kelas vokal Pop Jazz lanjut I atas nama Bening Gupita Esti, yang akan menyanyikan lagu Jazz berjudul I'm Beginning To See The Light yang dipopulerkan oleh Ella Fitzgerald. Pada lagu tersebut proses pembuatan iringannya sama seperti lagu I Surender. Akan tetapi untuk lagu tersebut hanya diturunkan $(-1.00)$ atau turun $1 / 2$ nada, jika lagu aslinya dengan nada dasar do=F, sehingga menjadi nada dasar $d o=$ E. Gambar 14 merupakan proses pembelajaran praktik vokal dengan lagu I'm Beginning To See The Light atas nama Bening Gupita Esti.

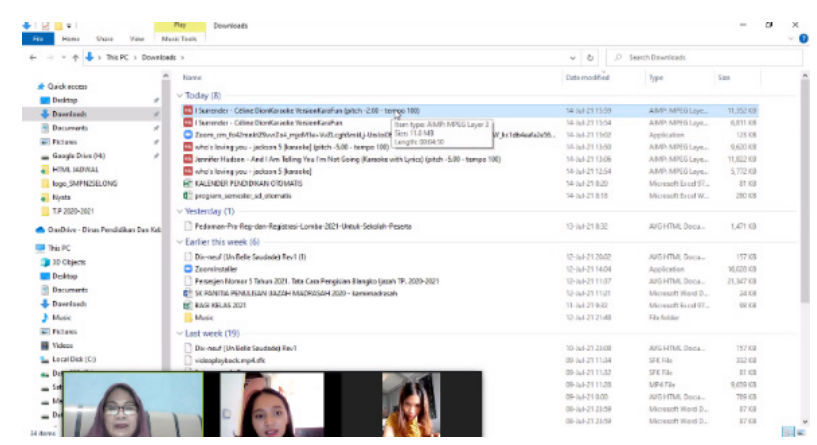

Gambar 12: Tampilan Music Speed Changer di layar File yang terbaru.

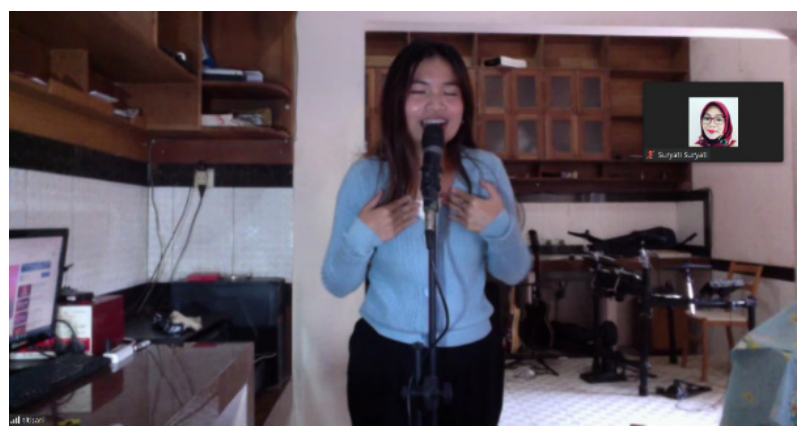

Gambar 13: Praktik vokal lagu pop I Surender atas nama Titisari Teresa.

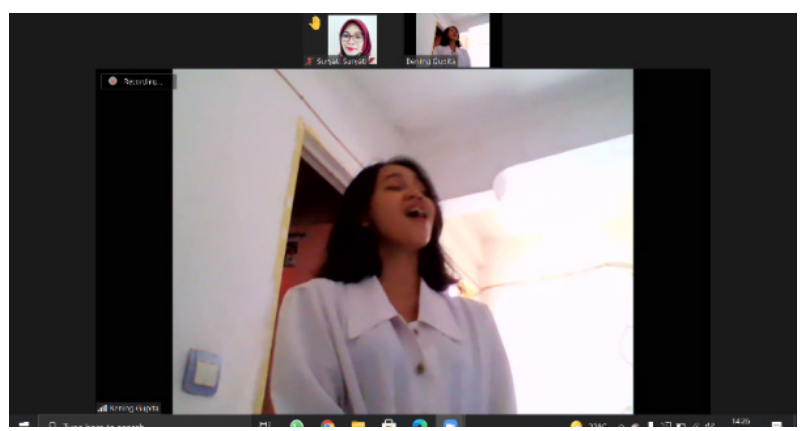

Gambar 14: Praktik vokal lagu jazz I'm Beginning to See The Light atas nama Bening Gupita Esti. 
Pembelajaran praktik vokal Pop Jazz lanjut I dengan jumlah 8 mahasiswa tersebut, kesemuanya memanfaatkan YouTube dan melalui proses yang sama dalam mencari iringan untuk praktik, seperti halnya yang dilakukan oleh Titisari dan Bening Gupita Esti. Akan tetapi pemanfatan YouTube sebagai media pembelajaran praktik vokal Pop Jazz lanjut I, tentu saja ada kekurangan dan kelebihannya. Kelebihan dari pemanfaatan YouTube sebagai media pembelajaran khususnya iringan dalam praktik vokal, dapat membantu mahasiswa belajar mandiri secara berulang-ulang ditempatnya masing-masing. Selain itu juga pembelajaran lebih efektif dan efisien, karena mahasiswa tidak mengeluarkan biaya untuk mencari pengiring. Metode yang digunakan dan situasi yang diciptakan dapat menjadikan suatu pembelajaran yang efektif dan efisien. (Wadiyo \& Utomo, 2018). Kelebihan yang lain mahasiswa dapat mengontrol emosinya dalam memberikan improvisasi saat menyanyikan lagu yang dipilih. Kekurangan dari pemanfaatan YouTube sebagai media pembelajaran khususnya iringan dalam praktik vokal, mahasiswa kurang bebas atau kurang leluasa dalam memberikan improvisasi saat bernyanyi, karena terbatas dengan iringan yang sudah secara otomatis. Dalam hal ini penyanyi menyesuaikan iringan yang sudah ada, berbeda dengan iringan yang secara live pengiring bisa menginguti penyanyinya.

\section{Kesimpulan}

Berdasarkan pemaparan hasil yang telah dicapai dari penelitian yang berjudul "pemanfaatan YouTube sebagai media pembelajaran praktik vokal Pop Jazz di Prodi Pendidikan Institut Seni Indonesia Yogyakata", maka dapat disimpulkan dalam dua permasalahan. Pada permasalahan pertama bahwa proses pembelajaran secara daring dan luring praktik vokal Pop Jazz lanjut I yang dilakukan selama 16 pertemuan diperlukan sebuah iringan musik. Iringan musik dalam proses pembelajaran praktik vokal Pop Jazz memanfaatkan aplikasi YouTube karaoke sebagai media iringan, baik dalam proses pembelajaran, Ujian Tengah Semester maupun Ujian Akhir Semester. Iringan YouTube karaoke tersebut tentu saja tidak semua sesuai dengan tinggi rendah suara yang diinginkan. Oleh karena itu, digunakan aplikasi music speed changer untuk menurunkan atau menaikan suara.

Proses pemanfaatan YouTube sebagai media iringan dalam praktik vokal, dilakukan dengan beberapa tahapan. Pada tahapan tersebut diawali dengan men-download di aplikasi YouTube karaoke lagu yang akan dinyanyiakan. Tahapan selanjutnya meng-convert lagu yang sudah di download ke Mp3 pada aplikasi YouTube to Mp3 Converter. Kemudian dilanjutkan dengan tahapan berikutnya pada aplikasi Music Speed Changer untuk menaikan atau menurunkan suara sesuai yang dikehendaki. Setelah berhasil melalui beberapa tahapan tersebut, maka sudah bisa digunakan sebagai media iringan. Namun dengan pemanfatan YouTube sebagai media pembelajaran praktik vokal Pop Jazz lanjut I, terdapat kekurangan dan kelebihan. Kelebihannya mahasiswa dapat belajar secara mandiri, lebih efektif dan efisien. Kekurangannya mahasiswa kurang leluasa dalam memberikan improvisasi saat bernyanyi, karena terbatas dengan iringan.

\section{Ucapan Terima Kasih}

Ucapan terima kasih disampaikan kepada Prof. Drs. Triyono Bramantyo, P. hd. dan Dr. Nursahid atas segala bimbingan, arahan, dukungan, motivasi dan masukan pada saat penyusunan artikel ini, dan trima kasih juga disampaikan untuk UPT Perpustakaan Institut Seni Indonesia Yogyakarta yang telah menyediakan berbagai macam bacaan yang sangat membantu dalam proses penulisan.

\section{Daftar Pustaka}

Africa, S., Development, S. A., Acyl, F., Free, T., Area, T., Summit, T., Committee, T. S., Tfta, T., Community, E. A., African, S., Community, D., Market, C., Africa, S., Africa, S., Union, A., Tfta, T., Fta, G., Summit, T., Secretary, C., Summary, E. (2020). Efektivitas Pembelajaran Basis Online di IAIN Tulungagung dengan Adanya Kebijakan Physical Distancing Era Pandemi Covid 19 Alifarose. GERAM (Gerakan Aktif Menulis), 3(1), 1-8. http:// search.ebscohost.com/login.aspx?direct=tru 
e\&Auth Type $=$ ip,shib\&db=bth \&AN=9294 $8285 \&$ site $=$ eds-live \&scope $=$ site $\% 0 A h t t p: / /$ bimpactassessment.net/sites/all/themes/ bcorp_impact/pdfs/em_stakeholder_ engagement.pdf\%0Ahttps://www.glo-bus. com/help/helpFiles/CDJ-Pa

B. Koapaha, R. (2013). Pembelajaran Komposisi Untuk Bidang Konsentrasi Pop-Jazz Dalam Kurikulum Sarjana Musik. Promusika, 25. https://doi.org/10.24821/pro.v0i0.537

Bintarto, A. G. (2014). Aspek Olah Vokal Musik Klasik Barat pada Musik Populer. Journal of Urban Society's Arts, 1(1), 44-56. https://doi. org/10.24821/jousa.v1i1.787

Gustianingrum, P. W., \& Affandi, I. (2016). Memaknai Nilai Kesenian Kuda Renggong dalam Upaya Melestarikan Budaya Daerah di Kabupten Sumedang. Journal of Urban Society's Arts, 3(1), 27-35. https://doi.org/10.24821/ jousa.v3i1.1474

Herliandry, L. D., Nurhasanah, N., Suban, M. E., \& Kuswanto, H. (2020). Pembelajaran Pada Masa Pandemi Covid-19. JTP - Jurnal Teknologi Pendidikan, 22(1), 65-70. https:// doi.org/10.21009/jtp.v22i1.15286

Meinawati, K. L. (2020). Pemanfaatan YouTube Dalam Meningkatkan Kompetensi Tutor Bimbel Edu Private. Comm-Edu (Community Education Journal), 3(1), 19. https://doi. org/10.22460/comm-edu.v3i1.3697

Mujianto, H. (2019). Pemanfaatan YouTube Sebagai Media Ajar Dalam Meningkatkan Minat Dan Motivasi Belajar. Jurnal Komunikasi Hasil Pemikiran Dan Penelitian, 5(1), 135-159. www.journal.uniga.ac.id

Pandaleke, S. M., \& Jazuli, M. (2016). Catharsis: Journal of Arts Education. Catharsis: Journal of Arts Education, 5(1), 41-47.

Pujiasih, E. (2020). Membangun Generasi Emas Dengan Variasi Pembelajaran Online Di Masa Pandemi Covid-19. Ideguru: Jurnal Karya Ilmiah Guru, 5(1), 42-48. https://doi. org/10.51169/ideguru.v5i1.136

Purwandari, E. (2019). Pemanfaatan YouTube sebagai Sumber Belajar Fisika. JOEAI (Journal of Education and Instruction), 2(2), 83-90. https://doi.org/10.1007/s11273-020-09706

Putri Sola, Johar, A., \& Farady, F. (2015). Berbasis Teknologi Informasi Dan Keterampilan Kelas 7 Di. Universitas Bengkulu, 3(1), 37-43.

Raharja, B. (2021). Pembelajaran Dolanan Jawa Berbasis Pilar-pilar Pendidikan bagi Anak Usia Dini. Resital: Jurnal Seni Pertunjukan, 21(3), 150-162. https://doi.org/10.24821/resital. v21i3.4611

Rizkiansyah, I. (2015). Pengembangan Aplikasi Pembelajaran Ineraktif Teknik Bermain Piano Berbasis Multimedia di Lembaga Kursus Musik "Ethnictro" Yogyakarta. Jurnal Informatika.

Sugiyono. (2011). Metode Penelitian Kuantitatif, Kualitatif dan R\&D. Alfabeta, CV.

Wadiyo, W., \& Utomo, U. (2018). Pengembangan Materi Ajar Seni Budaya Sub Materi Musik pada Sekolah Umum Jenjang Pendidikan Dasar. Resital: Jurnal Seni Pertunjukan, 17(2), 87-97. https://doi.org/10.24821/resital. v17i2.2221

Yudiawan, A. (2020). Belajar Bersama Covid-19: Evaluasi Pembelajaran Daring Era Pandemi di Perguruan Tinggi Keagamaan Islam Negeri, Papua Barat. AL-FIKR: Jurnal Pendidikan Islam, 6(1), 10-16. https://doi.org/10.32489/ alfikr.v6i1.64 